\title{
Reflections of the student teacher
}

\begin{abstract}
This paper explores the concept of reflection and its changing role in the journey of the student teacher. It presents part of the findings of a yearlong investigation into the reflective practice of student teachers during their training year. Specifically it investigates the reflections of the student teachers' lessons during the PGCE (Post/Professional Graduate Certificate of Education) year at a HE institution in England. The strengths and weaknesses of the student teachers' lessons are analysed and how these reflections change as they reach Newly Qualified Teachers (NQT) status.
\end{abstract}

\section{Introduction}

Interpretations of reflective practice vary between different professions and even within the same professional field, such as education. There are some areas of agreement and these are that reflective practice is the 'process of learning through and from experience towards greater insights of self or practice' (Finlay, 2008, p.1). The process of learning is the basis for all interpretations of the contentious term, and whatever form reflective practice takes the reflective practitioner should learn and grow from engaging with it. Reflective practice is used within teacher education to enable the student teacher to learn and develop (PoomValickis \& Mathews, 2013).

In England the teaching standards focus on 'reflection' and the importance of striving to produce the best lesson. There are many advocates of encouraging critical reflection in initial teacher education (ITE) and there are valid arguments for this (Lam, 2015; Liu, 2015; Elbaza, 1988); however at present critical reflection is not part of the teaching standards and this paper will focus on reflection and its changing nature during the Post/Professional Graduate Certificate of Education (PGCE) year. Reflection was reaffirmed as an important part of being a professional teacher and was one of the 2012 teaching standards (DfE, 2012a, no page number):

... [a teacher must] reflect systematically on the effectiveness of lessons and approaches to teaching. 
According to Khan (2015) this teaching standard is often met by evidencing the evaluation of lessons. This learning from actual teaching is often referred to as the 'technical approach to reflective practice' and includes reflecting on how the lesson objectives were met and to what extent learning occurred (Meierdirk, 2016, p.2).

For this research study the interpretation of 'reflection' is based on the first stage of Finlay's (2008) reflective practice continuum (Figure 1). The overall research project investigated all three dimensions of Finlay's (2008) reflective practice but, due to the amount of data this created, this paper will only focus on the first stage of the continuum: the reflections of the student teacher. This was examined through the research question: How do the reflections of the student teacher change during the PGCE year? The continuum contains a three stage definition of reflective practice. The first stage is reflection, which is when the student teacher reflects on their own lessons and evaluates them. The second stage is critical reflection, when the student teacher reflects on the impact of the social world that surrounds them by looking at the role of power and the social field the student finds themselves in (Schon, 1987, Bourdieu, 1990). Reflexivity is the last stage of the reflective practice continuum, and is when the student teacher reflects on their identity and the need to reconstruct it due to the changing environment (Archer, 2007).

Insert figure 1 here

Reflection can be broken down into five different types (Fig 2). The first three levels were developed by Schon (1995) : 'knowing in action', 'reflection in action', and 'reflection on action'; the last two, 'reflection for action' and 'reflection with action' were added by Ghaye (2010).

Insert figure 2 here 
'Knowing-in-action' is the unconscious reflective practice that occurs when a person's acts are based on prior experience. The person does not actively reflect on the event but uses tacit knowledge before engaging in action. Eraut (1994) refers to knowing in action as tacit knowledge, as it is the knowledge gained through experience that dictates how a student teacher behaves and reacts. As the student teacher moves to a becoming a professional their tacit knowledge increases and influences their actions.

'Reflection-in-action' is a conscious reflection that is undertaken 'on the spot'; it is a reaction to what is occurring at the time, rather than an instant reaction using tacit knowledge. Schon's (1991) reflection-on-action occurs after the event and is a continual process of review and improvement. Schon $(1987$, p.40) developed a three stage model for reflectionon-action:

1. Providing students with technical training

2. Helping the students think like a professional

3. Enabling the students to develop a new form of understanding and action

The practitioner is encouraged to use reflection-on-action by continuously reflecting on a problem to generate new knowledge. This new knowledge is then used to solve a problem or dilemma. Schon (1987) advocated that problems are solved by thinking through the reflection process. According to Schon this cyclical process would improve the standard of the professional experts in their field.

Ghaye (2010) builds on Schon's 'reflection on practice' and adds two more types of reflection: 'reflection for action' and 'reflection with action'. Reflection for action is the implementation of an action that occurs after the reflection on action has been undertaken. Reflection for action is the implementation of an action that occurs after the reflection on action has been undertaken. The student teachers undertake continuous improvement and this manifests itself as a cyclical process (Fig. 3). 
Murray (2010) refers to reflective practice having two levels: individual and collaborative. 'Individual' happens when a teacher reflects by oneself and 'collaborative' consists of activities such as peer mentoring, coaching and support groups. On the PGCE course reflections may occur in discussion between the student teacher and their subject mentor, tutor or peers. When the student teacher has a lesson observed it may be followed by a joint discussion with the student teacher and the observer. The joint discussion may involve identifying areas that were successful and areas for improvement and teaching strategies are often set based on these areas. This would be an example of 'reflection with action' as it involves joint discussion on strategies to improve. Naci Kayaoğlu, Erbay \& Sağlamel (2016) researched the student teacher's journey and found that the mentor had a positive impact on the novice teacher but they limited the teacher's reflections if they did not match their own beliefs.

\section{Research context}

This research is situated at a HE institution in South East England. The case study participants were part of the overall PGCE programme. At the University, the PGCE is a full time, one year course that enables a graduate student to become a newly qualified teacher (NQT). The PGCE is one of the routes into the teaching profession in England. The student can pass at Level 6 of the framework for higher education award bodies in England, Wales and Northern Ireland (FHEQ), and obtain a Professional Certificate in Education, or pass at Level 7, after obtaining a Postgraduate Certificate in Education. Both the postgraduate and professional route leads to qualified teacher status (QTS).

The HEI has a relatively small cohort of PGCE students with around 100 students enrolled every year. Seven different PGCE subjects are taught: English, Modern Foreign Language (MFL), Mathematics, Science, Business, Geography with Computer Science added in September 2015. All these subjects cover the 12-16 age groups except Business, which is taught to the 14-19 age range. The structure of the PGCE course is the same for all the courses. Figure 4 illustrates how the student teacher's time is divided between professional studies, curriculum studies and the school experience. The students arrive during the first week in September each year and study 'professional' and 'curriculum' studies. Professional 
studies cover areas that are important for all the PGCE students, such as the National Curriculum, government policies, learning theories and behaviour management.

\section{Insert figure 4 here}

'Curriculum Studies' are the subjects that are specific to the PGCE subject area. The student teacher will attend seminars on areas specific to their teaching, for example teaching the academically more able in Business or applying Bloom's (1956) taxonomy. About one third of the PGCE year is spent at the university and the rest of the time the student teacher is in their placement(s).

After the first three weeks of the PGCE course the student teacher will start at their first placement (phase 1). After Christmas they start phase 2, with a placement in a different school/college, and after Easter, phase 3 in the same school as phase 2. The student teacher stays at the same placement for the last two teaching phases, unless there is a reason to move them to another school/college.

In phase 1 the student teacher is given substantial assistance by the school mentor during the first few weeks of their school experience. The students observe, assist in the classroom and engage in collaborative teaching with some small scale supported teaching. After the October break the student teacher is in school five days a week and most students are involved with eight hours a week of whole class teaching and six hours of observing and supporting other classes.

In phase 2 , the classroom teaching and learning activities are jointly planned by the mentor and student teacher. The student teacher should maintain a timetable that is approximately 10-12 hours teaching per week over four days, with three hours of observing and supporting in other classes. The student teacher is expected to observe taught lessons and help within the classroom with small groups as well as with whole classes. From February half-term, when the student teachers are in school five days a week, most students are maintaining a whole class teaching timetable of approximately 12 hours with three hours of other classroom experience. 
In phase 3, student teachers will be planning their classroom and school focussed work more independently. The student teacher's timetable will remain at 12 hours per week and more independence should be demonstrated in order to achieve the teaching standards. The mentor exercises their professional judgement as to how much autonomy a student teacher can be given while maintaining the quality of teaching. The student teacher will be expected to observe other teachers and lessons for another three hours.

\section{Methodology}

The student teacher's reflections were researched using an exploratory case study $(n=6)$. The exploratory case study investigates the behaviours within a case and its surrounding context (Yin, 2003). One of the main critiques of case study research is that it is difficult to generalise from the results as they are unique to a given space and time. Smith (1991) identifies the significant problems a legitimate case study has to conquer. Like other research methods, a case study has to demonstrate reliability and validity. The uniqueness of a case study has the advantage of producing rich descriptions but with the disadvantage of limited breadth. By comparison, Zucker argues (2009) a quantitative approach to research produces external validation but lacks depth.

The case study design was chosen, as this study investigates reflective practice in a real life context. It is exploratory research as an 'in-depth' study was needed to be carried out on the phenomenon of reflection. Yin (2003) identifies a number of different types of case study: descriptive, explanatory and exploratory. An illustrative case study is a descriptive account of a real life event that reinforces an argument. The explanatory case study explains why certain behaviours occur and may identify the variables that cause the behaviour. The research objective was explorative; and so was suited to an exploratory case study which would enable me to gain a greater understanding of reflective practice in its context by producing rich data from the student teachers' responses.

The data collection methods used in the case study were: semi-structured interviews and reflective practice sheets. The reflective practice sheets enabled an investigation into reflection which encapsulated: refection on action, reflection for action and refection with action (Schon, 1987, Ghaye, 2010). 'Knowing' and 'reflection in action' is unconscious 
action and so would be difficult to observe through interviews and reflective practice sheets as both these methods happened after lessons were taught. The reflections by the student teachers on the reflective practice sheets centred round the student teacher's weaknesses and strengths. Over 100 reflective practice sheets were examined with over 1,000 reflective comments coded and analysed. All six case study participants completed reflective practice sheets during the PGCE year. These were developed at the start of the academic year (Appendix). The reflective practice sheets replicated Ghaye's (2010) reflection for action and were divided into four segments illustrating the cycle of reflection (Fig. 5). The student teachers identified their strengths and weaknesses of their lesson. From the weaknesses the student identified strategies to improve and targets were set for the subsequent lesson.

\section{Insert figure 5 here}

The reflective practice sheets allowed me to analyse the student teacher's 'reflections'. The sheets highlighted the issues the student teachers were reflecting on, and when they were reflecting on them, during the year. Twenty one case study interviews were conducted. The interviews were semi-structured with questions that were planned, in advance, but with the freedom of flexibility if topics arose that needed further investigation. This data allowed me to analyse and highlight any patterns that emerged in the student's reflections.

The interviews designed for this case study were semi-structured with open ended questions. They were designed to allow the student teachers time to expand on their answers but within a question schedule. At times there were supplementary questions posed when it was felt that it might give greater insight into the research. This is illustrated in Table 1 in an extract from Student A's January interview. She was answering the question: 'What does education mean to you?' Her answer led to my further question concerning whether or not her family's past belief influenced her own belief.

Insert table 1 here 
The semi-structured interview produces an exchange of conversation and dialogue between the interviewer and participant. This approach allowed me to focus on the participant's 'perception of self, life and experience' in their own words (Minichiello, 1995, p.52). The interviews produced rich data about the student's understanding of reflective practice and allowed me to trace the journey they were on. One of the main goals of qualitative interviewing is to understand complex behaviour, opinions and thoughts that cannot be understood using direct observation and during the interviews I was fortunate to be able to listen to the student teachers' narratives about their journeys.

Defining a sample universe and its population was done by applying a set of inclusion and exclusion criteria. In this case the sample universe was students studying for a full time PGCE at a higher educational institution (HEI) in England. Because of the nature of the research, into reflective practice, the sample size needed to be small enough to locate the voice of the individual. Robinson (2013) recommended a sample size of between 3-16, as this provides scope to highlight cross case generalisations while preventing the researcher from becoming overwhelmed with data.

The selection process was also influenced by my sample strategy. There are two main sampling strategies that can be employed at this stage: random/convenience sampling and purposive sampling. Random sampling is the selection of cases randomly from the sample universe and is generally used in surveys. Convenience sampling is when the sample is selected on the basis of availability (Leedy, 2005). Based on the knowledge and expertise of the researcher the sample illustrated typical students that embarked on a PGCE course and were students that the researcher would have close contact with throughout the period of the research. Purposive sampling can take a number of forms, such as extreme sampling which is selecting 'illuminating cases' and intensity sampling which is the selection of 'rich samples' that are of interest to the research question (Patton, 2002, p.232). In this case the participants were both 'illuminating' and 'rich'. Six PGCE students were selected to be part of the case study. Sampling in case study research is different to sampling for surveys, as it is theoretical rather than statistical and seeks data that is rich and purposeful. In this case the participants were selected using a range of variables including gender, marital status, age, religion and parental status. These variables were selected to highlight any differences in reflective behaviour with regards to habitus and are the bases for the analysing the interview data (Table 2). 
Insert table 2 here

The following are summaries of the student teachers in the case study:

1. Student A was English, had spent many years in Human Resources before applying for the PGCE course. She had been a local government councillor for four years. Student A was 34 years old, married with two young children.

2. Student B was Irish and had a long term partner. She had a two year old daughter and came to England especially to obtain her PGCE. Her partner gained employment at a local firm during her PGCE year. Student B was 26 years old at the start of the course.

3. Student C applied for the 2009 course but was rejected at interview due to a lack of knowledge of teaching. She reapplied for the 2010 course after spending a year as a cover supervisor in an inner city school in Portsmouth. She went to a tough inner city school herself and then went to the local university. Interestingly, although English and from a white working class background, she embraced the Islamic faith after marrying and wore a hijab. Student $\mathrm{C}$ was married, 29 years old and had no children.

4. Student $\mathbf{D}$ was single. He was English and graduated from university and then spent a year as a cover supervisor in a local school before starting the PGCE course. He was 24 years old and had no children.

5. Student E was a mature student who was 49 years old. He was English and had been a manager at a top finance company for twenty years, and had run his own business. Student E had three grown up children, two grandchildren and was married.

6. Student $\mathbf{F}$ applied for the 2009 course but was rejected. It was felt he lacked the ability to control a class. He then spent a year as a teaching assistant in an inner city school before applying and starting the 2010 course. He was, English, 33, married with one son.

In total, 102 sheets were collected: 42 sheets in phase 1, 43 in phase 2 and 17 in phase 3 (Table 3). The majority of reflective practice sheets were completed in phase 2. The small number in phase 3 was, in part, because it only consisted of eight weeks of teaching. The 102 reflective practice sheets, with over 1,000 reflective comments, were coded and categorised. 
All the reflective comments on strengths and weaknesses were coded. The sheets were analysed using first and second cycle coding.

\section{Insert Table 3 here}

A code is a word or short phrase that symbolically assigns a summative, salient, essencecapturing or evocative attribute to a portion of language-based or visual data (Saldana, 2009, p.3). The 'portion of language' that is coded can be as long as a page or as short as a single word. The data can consist of transcripts, videos, artefacts and numerous other forms of data. In this instance (reflective practice sheets) the data took the written form. There is a personal approach to coding, known as 'the coding filter', as one researcher's interpretation may be different to another (Adler \& Goodman, 1987). As Sipe (2004, pp.482-3) stated all 'coding is a judgment call since we all bring our subjectivities, our personalities, our predispositions, [and] our quirks' to the processes.

One way to improve the consistency of the coding was to engage in reflexivity during the coding process. 'Constant comparison' was used to check the coding process and its validity. Constant comparison has greater validity when in vivo coding is used, as an actual word is taken from the text to name the code. An example of constant comparison was when comparing two reflections with the same code. Student E reflected (Phase 2): 'Net result was that a couple of students made good progress while the majority did not achieve to the same extent.' This was coded as 'outcomes' which was compared to another reflection by Student B which was also interpreted as 'outcomes' (Phase 2): 'Students made progress on planned activity. Pupil E and pupil N especially although they didn't like being given extra work.'

There were two cycles of coding in analysing the reflective practice sheets. The first cycle involved a mixture of in vivo, evaluative, descriptive and simultaneous coding. In vivo coding is when the code is based on a word or a series of words used within the text. An example of in vivo from the first cycle of coding was 'differentiation'. Student D reflected: 'Good initial differentiation developed through well targeted question and answers' (Phase 
1). This comment was coded as 'differentiation' as that word appears in the text. It is also an example of descriptive coding, as differentiation is what the comment was about.

Some of the text was coded using evaluative coding. If the student reflections were not about a certain topic area the text's meaning had to be interpreted. An example of this is shown by this reflective comment by Student B: '(The) majority of students were on task and not using games/mobiles especially pupil A. This was his first lesson he was not playing games' (Phase 2). This reflection was coded with a D for 'disruption'. The word 'disruption' is not written in the utterance but it was interpreted as such, and this is evaluative coding. Simultaneous coding was also used throughout the first cycle. Simultaneous coding is when a text is read and given more than one code. The following reflection by Student D was coded with 'resources', 'differentiation' and 'group work':

Group task to summarise the findings of the video clip worked well, but to achieve greater depth of answering, greater evaluations and (the) facilitation of peer learning, the groups need more differentiation in members. (Phase 2)

The first cycle of coding was also based on the subject area the student was reflecting on. This is exemplified by Student A whilst reflecting on a lesson:

(I) tried a more student centred approach using knowledge centres and splitting the class into groups. They worked well in their groups and understood the task. (Student A, Phase 2).

Using descriptive coding the utterance was given the code 'group work' and given the code 'Gr'. The 'Gr' coding was given to all other comments on group work that appeared in the reflective sheets. This method of coding was appropriate, as it enabled students' responses to be grouped and the first cycle of coding formed. After the first cycle of coding, 34 codes were established (Appendix).

After the initial primary codes were identified they were analysed again to establish relationships. Figure 3 shows the coding process for the reflective practice sheets. After the initial cycle of coding there were a number of primary codes that overlapped topic areas, for example lesson planning and lesson timings. Because of this overlap, five new categories were created (Table 4). 


\section{Insert Table 4 here}

Performance indicators included the first cycle codes that are part of performance management in schools. Performance culture dominates education: its structure, its culture and its discourse (Britzman, 1994). It was clear from the reflective practice sheets that performance discourse was present in the student's reflections and so it was decided to have 'performance indicators' as its own category. Ball (2004, p.145) defines performance as:

...a system of measures and indicators (signs) and sets of relationships, rather than on functions for the social systems and the economy.

And goes on to say it is about:

... value added, cost effective efficiency and effectiveness, measurement of achievement, learning outcomes, flexible delivery, markets...

In this case utterances that included reference to targets, assessment, outcomes and objectives were deemed 'performance indicators'.

\section{Research Analysis}

When analysing the reflective sheet data a number of trends were identified. In writing about their weaknesses, the student teachers' reflections on 'performance indicators' increased as they gained more experience. This was the same for all the student teachers in the case study. In fact analysing the students teachers' 'weaknesses', reflections on performance indicators increased proportionally more than any other category (Table 5). 
In the teaching standards only 2 of the 41 standards were 'performance indicators' but 'performance indicators' had more prominence in the reflections of the student teachers (DfE, 2012). This suggests the need to focus on 'performance' is coming from the environment of the student teacher rather than from the standards themselves. The student teacher belongs to different social fields where different agents are dominating. This change is reflected in the discourse the student teacher uses and the reflections they write.

In this analysis the discursive practices of the student teacher are an important focus. Attention is paid to the influence of social structures on the agency of the teacher thus concurring with Gee's (1990) viewpoint that discourse conveys a message regarding practice in a particular context. I believe the discourse of the student teacher reveals the relationship between the social agent, structure and practice. In this context 'agents' refer to individuals and their participation in social structures (Archer, 2007). Structures may be interpreted at both the personal and societal level. At the societal level structures may refer to large social systems whereas at the personal level they might refer to conceptual structures (Sayer, 1992). Structures can take different forms; they might be physical or a fusion of relationships between individuals.

Insert Table 6 here

Table 6 illustrates the overall reflections of strengths by the student teachers. In phase 1, behaviour management was reflected on as the student teachers' most dominant strength in both phase 2 and 3. Its importance, as a' strength', illustrates the student teacher's ability to manage pupil behaviour. Around 32\% (phase 3) of all reflections are on pupil behaviour compared to just over $10 \%$ of the teaching standards (DfE, 2012). 
The student teachers used different narratives when writing about the pupils. Student A's discourse illustrated a 'them and us' approach to her classes, especially in phase 2. She struggled with behaviour management, but used an authoritarian approach to conquer this problem:

I was in control of the class and continued to assert my authority on them (Student A, Phase 3)

Student $\mathrm{C}$, however, took a more personal approach in her reflective comments and referred to pupils individually compared to the other respondents:

My rapport with the class and understanding that I will help and not be judgmental... (Student C, Phase 1)

Good environment and atmosphere within the lesson which made it enjoyable. (Student C, Phase 3)

Student C named individual pupils in her reflective practice sheets. She reflected on how she managed their behaviour and what strategies would improve their relationship. Her comments showed a more personal attachment to the class she was teaching and a need to build relationships between her and the pupils.

All the student teachers used behaviour management strategies at the start of their PGCE year, such as developing classroom rules, seating plans, detentions and behaviour points. This is highlighted by Student B's strategy in phase 1 '...take note of pupils arriving late to lesson and give out discipline procedures and follow through with 10 minute detention'. Behaviour management strategies were commented on frequently by the students, but as they became more experienced they started to develop strategies that were more personalised. Students A, B, C, D and E all used differentiated material and exercises as a strategy in phase 2, but not in phase 1. A good example of a strategy was provided by Student C: 'Plan extension tasks and learning objectives which are pitched at a higher level' and 'create pair/group work activities or whole class games through plenaries' (Phase 2). The emphasis on classroom rules, as a strategy for disruptive pupils, was replaced with differentiation of resources. Differentiation of resources was used after the more traditional strategies were implemented. These findings concur with a study conducted by Poom-Valickis and Mathews 
(2013) who found novice teachers tended to use their authority to try and control a class rather than 'tools' due to limited experience. The reflective sheets in this study actually show the 'tools' that are developed and used as the student teachers become more experienced.

Although the reflections are presented as percentages in the above tables ( 5 and 6 ) there was a definite trend to use the reflective practice sheets less as the student teacher became more experienced. A number of student teachers explained that it was because they began to reflect in their minds. Student D commented in the June interview: 'I use them (reflective practice sheets) less in reflecting, but I think reflecting just one-on-one by myself, in my mind has increased'. Student D may have been reflecting more but, due to time constraints, was not writing it down. This concurs with Eraut's (1995) research findings that reflective practice is time determined. Eraut criticised Schon's (1987) theories on reflective practice as not allowing for the effect of time. The exact same trend was seen with all the students except Student F. They all reflected, in the interviews, that their reflective practice was becoming subconscious:

I suppose it has had a role. I've thought, you know I, I mean I think I've tried to as the year's gone on to be less negative in my reflective practice and be more positive and try and see things. I'm not a person who takes criticism well, I do know that about myself and I have tried to take it a little bit better <smiles>. I think it has been, throughout the year it has been something that I have used, maybe subconsciously, as much as anything, in that afterwards I've been able to process information and think about it without emotion, perhaps, and understand things a little bit better in seeing where things have gone wrong and right and stuff. (Student A, Phase 3)

It would be difficult to 'reflect subconsciously' and know you are doing it, but Student A seems to be alluding to reflective activities occurring in the mind rather than in written form. This reflecting 'in the mind' is an example of Schon's (1987) 'reflection in action' as the student teachers are reflecting quickly to solve a problem. Eventually this reflection will become tacit knowledge or 'knowing in action' and will no longer be consciously reflected on at all.

'Reflection with action' was embedded into the teacher education programme. The students reflected upon their lessons with a number of people. They reflected with their subject mentor, their professional mentor and other teachers in the subject department. The analysis of this research data shows there are many other people involved in the reflective process. 
All the student teachers reflected with each other, either at university or socially. The students shared resources in order to 'bounce ideas' off each other. This group's reflectivity was important for the student teacher's progression and support. They needed experience and ideas in order to develop their lessons further. When engaging in 'reflection on practice' the more ideas the student teacher has the more options they have to improve their practice.

All the student teachers reflected on how important support was from other people. The students found it important to talk through issues with people outside of the course. This support was invaluable in enabling them to complete the year (Figure 6). Student E highlighted the need for this support when reflecting with his wife; he reflected that it was important 'just to have somebody to talk to about things ..cause I would say, sort of, being in a placement in the school is quite a lonely place' (May, 2011).

\section{Insert figure 6 here}

Figure 6 illustrates the people the student teachers reflected with outside the PGCE course. Being able to reflect with others outside the inner community, of the PGCE, was important for the students because, as stated:

...you're very conscious that you're being assessed and appraised all the time and you, you might not necessarily want to be as open within that process as you might be if you were a permanent fixture within the department, so you're sort of trying to... faking it good to keep... manage your own PR within the situation...(Student E)

Student E explained that reflecting within the inner circle was limited, due to social constraints (Fig. 7). These constraints reflect the nature of the 'social fields' the students find themselves part of (Bourdieu, 1977). All the agents in the 'inner field' have power over the student teacher and contribute to his/her grading and assessment.

\section{Insert figure 7}




\section{Discussion and conclusion}

This paper presents part of the findings from a larger study and concentrated on the reflections of student teachers. During the PGCE year the student teachers continually reflect on their lessons; as they engage in reflection they evaluate their lessons and set targets for the next lesson. This process continues throughout the year as the student gains experience. All the student teachers need to reflect on their lessons to meet the teaching standards; however, the way the reflection develops is different for individual students. Student D (February interview), who was familiar with reflecting from years in industry, found he was reflecting 'in his head by February':

Yeah, even if it's not on... written down on paper. There are times when I will be constantly thinking about that and ... and I'd say I'm not a very self-critical.

With other student teachers this did not occur until after Easter and Student F still felt the need to write his reflections down in the last phase:

...actually reflective on, on what I do and write, you know, and, and committing that to, to writing. I think it's been really useful and there's cert, you know the, especially the circular stuff has been, has been really useful in identifying what I've done.

Student F was the lowest graded student teacher and there is a possible link here between the ability of the student teacher and how far their reflections have progressed from 'fully thought out' strategies on paper to ones that occur quickly in the mind. According to the student teachers there was also a need to reflect quickly because there was so much pressure on them:

I just think I got distracted by everything else that I then saw that was a priority rather than reflective practice; such as your lesson planning, any other duties that come within being a teacher etc....

Therefore the evidence suggests that reflective cycles are much quicker once the student gains experience and knowledge. This enables them to become quicker at reflecting on lessons and moves reflection from a written activity to a thinking one. As the student's experience increases they draw upon more knowledge and practice thus allowing the reflections to be quicker. 
The student teachers used reflection to improve their teaching. They focused on a myriad of areas and these were categorised into: classroom activities, lesson planning, behaviour management, performance indicators and their teaching role. This reflection occurred throughout the PGCE year, influenced by the teaching standards they were working towards, to gain QTS. The student teachers reflected less through their reflective practice sheets as the year progressed. This was due first to lack of time. The students found they were under considerable time pressure planning lessons and did not feel able to actively reflect as much. Secondly, the student teachers used their reflective sheets less because they reflected unconsciously. They believed they no longer needed to write their reflections and strategies down. This 'reflecting in the mind' coincides with Schon's (1987) 'knowing in action'. Knowing in action is tacit knowledge; the practical knowledge gained that is observable but difficult for the practitioner to explain. Quite a few of the reflective topics were reflected on less as the student teachers gained more knowledge. This was most noticeable in designing 'classroom activities' and the 'role of the teacher'.

The role of the social environment and its impact became an important part of this study, as individuals do not act in isolation. The student teachers' narratives are a product of the social environment, and this was reflected in the students' discourse. Analysis of the reflective practice sheets revealed that the student teachers became more concerned with performance targets as they gained more experience. Reflections on topics such as targets, objectives, outcomes and assessment became more frequent. In phase 1 the student teachers still talked about their feelings about education and their role, but by the end of the year they had stopped reflecting on their educational ideologies; instead, performance discourse gained more presence. There are numerous accountability structures in the social structure of education and the discourse of these structures is reflected in the reflections of the teacher.

The student teachers discussed the importance of support while on the PGCE course. This support came from the 'inner circle', which included the university tutor, subject mentor, other teachers in the placement and other PGCE students. This support, however, came with 'catches'. The inner circle or immediate 'field of play' for the student teacher had micro politics attached. The student teacher could not talk freely in this immediate 'field of play' as they were reflecting with dominant agents who controlled those fields (Bourdieu, 1977). This meant that the student teacher also needed a layer of support from agents outside this 'inner 
circle': parents, partners and friends. This reflection with practice was not always with a knowledgeable other but a 'supportive other'. 


\section{References:}

Adler, S., \& Goodman, J. (1986). Critical theory as a foundation for methods courses. Journal of Teacher Education, 37, 2-8.

Archer, M. S. (2007). Making our way through the world: human reflexivity and social mobility. Cambridge: Cambridge University Press.

Ball, S. J. (2004). The RoutledgeFalmer reader in sociology of education. London: Routledge Falmer.

Bloom, B. D., \& Krathwohl, D. R. (1956). Taxonomy of educational objectives: The classification of educational goals by a committee of college and university examiners. Handbook 1. Cognitive domain. New York: Addison Wesley.

Bourdieu, P. (1977). Outline of a theory of practice. R. Nice (trans.), Cambridge: Cambridge University Press.

Bourdieu, P., \& Passerson, J. C. (1977). Reproduction in education, culture and society. (R. Nice trans.). London: Sage.

Bourdieu, P. (1990). The logic of practice. Cambridge: Polity.

Britzman, D. (1994). Programmatic Structures for the Preparation of Reflective Teachers, Urbana, Ill., National Conference on Research in English: National Council of Teachers in English.

Denise, E. de S. (2014). Culture, context and society - The underexplored potential of critical realism as a philosophical framework for theory and practice. Asian Journal of Social Psychology. 17 (2), 141-151.

DfE. (2012a). Teachers' Standards. DfE. Crown Copyright: London.

Elbaza, F. (1988). Critical Reflection on Teaching: insights from Freire. Journal of Education for Teaching, (14) 2, 171-181.

Eraut, M. (1994). Developing professional knowledge and competence. London, Falmer.

Eraut, M. (1995). Schon Shock: a case for refraining reflection-in-action? Teachers and Teaching, 1(1), 9-22.

Falter Thomas, A.; Sondergeld, T. (2015). Investigating the Impact of Feedback Instruction: Partnering Preservice Teachers with Middle School Students to Provide Digital, Scaffolded Feedback. Journal of the Scholarship of Teaching and Learning, (15)4, 83-109.

Finlay, L. (2003), Negotiating the swamp: the opportunity and challenge of reflexivity in research practice. Qualitative Research, August 2002, 2, 209-230.

Finlay, L. (2008). Reflecting on reflective practice. PBPL. 
Gee, J.P. (1990). Social linguistics and literacies: Ideology in discourse. London: Falmer.

Ghaye, T. (2010). Teaching and learning through reflective practice: a practical guide for positive action. London: Routledge.

Khan, M. (2015), Impediments to Reflection in Teacher Education: A UK Case. FWU Journal of Social Sciences. 15 (9), 22-31.

Lam, K. D. (2015). Teaching for Liberation: Critical Reflections in Teacher Education. Multicultural Perspectives, 17 (3), 157-162.

Leedy, P. D. O. (2005). Practical research: Planning and design. Upper Saddle River, NJ: Prentice Hall.

Liu, K. (2015), Critical reflection as a framework for transformative learning in teacher education. Educational Review, 67 (2), 135-157.

Loughran, J. J. (1996). Developing reflective practice: Learning about teaching and learning through modelling. London: Falmer Press.

Mansell, W. (2007). Education by numbers: the tyranny of testing. London: Politico's.

Meierdirk, C. (2016). Is reflective practice an essential component of becoming a professional teacher. Reflective Practice: International and Multidisciplinary Perspectives, 17(3), 1-10.

Minichiello, V. (1995). In-depth interviewing : principles, techniques, analysis. Melbourne: Longman.

Murray, A. (2010). Empowering Teachers through Professional Development. English Teaching Forum, 48(1), 2-11.

Naci Kayaoğlu, M., Erbay, Ş., \& Sağlamel, H. (2016). Gaining insight into a novice teacher's initial journey through reflective practice. Reflective Practice, 1 (15), 167-181.

Patton, M. Q. (2002). Qualitative Research and Evaluation Methods. Thousand Oaks, CA: Sage.

Poom-Valickis, K., \& Mathews, S. (2013). Reflecting others and own practice: an analysis of novice teachers' reflection skills. Reflective Practice, 14 (3), 420-434.

Robinson, O. C. (2013). Sampling in Interview-Based Qualitative Research: A Theoretical and Practical Guide. Qualitative Research in Psychology, 11(1), 25-41.

Sayer, A. (1992). Method in social science: A realist approach. London: Routledge.

Schon, D. A. (1995). Reflective practitioner: how professionals think in action, Arena.

Schon, D. A. (1991). The reflective practitioner: how professionals think in action. 
Aldershot: Avebury.

Schon, D. A. (1987). Educating the reflective practitioner. San Francisco, CA: Jossey-Bass.

Savage, J., \& Fautley, M. (2010). Secondary education reflective reader. Exeter: Learning Matters.

Sipe, L. G. (2004). Developing conceptual categories in classroom descriptive research: Some problems and possibilities. Anthropology and Education Quarterly, 35(4): 472485

Smith, H. W. (1991). Strategies of Social Research. Orlando Florida: Holt, Rinehart and Winston.

Yin, R. K. (2003). Case study research: design and methods. Thousand Oaks, Calif.; London: SAGE.

Zucker, D. (2009). How to Do Case Study Research. School of Nursing Faculty Publication Series, University of Massachusetts: Paper 2. 
Appendix A: First cycle coding

\begin{tabular}{|l|l|l|l|}
\hline Preliminary coding & Code & Preliminary coding & Code \\
\hline Questioning & Q & Lesson objectives & Ob \\
\hline Resources & CR & Pupils' names & Nm \\
\hline Support & $\mathrm{S}$ & External interruptions & $\mathrm{E}$ \\
\hline Presence & $\mathrm{P}$ & Speech & $\mathrm{Sp}$ \\
\hline Disruption & $\mathrm{D}$ & Outcomes & $\mathrm{O}$ \\
\hline $\begin{array}{l}\text { Pupil personalisation/ } \\
\text { Differentiation }\end{array}$ & $\mathrm{Pn} /$ Dif & Computers & $\mathrm{Pc}$ \\
\hline Assessment & $\mathrm{Ass}$ & Subject knowledge & $\mathrm{Sk}$ \\
\hline Extension & $\mathrm{Ext}$ & Note taking & $\mathrm{Nt}$ \\
\hline Teaching assistant & $\mathrm{Ta}$ & Group work & $\mathrm{Gr}$ \\
\hline Lesson plan & $\mathrm{Lp}$ & Lateness & $\mathrm{L}$ \\
\hline Teacher led & $\mathrm{Tl}$ & Targets & $\mathrm{T}$ \\
\hline Pupil focus & $\mathrm{F}$ & Gender & $\mathrm{Gen}$ \\
\hline Starter activity & $\mathrm{Sr}$ & Instructions & $\mathrm{I}$ \\
\hline Rules of the classroom & $\mathrm{Rc}$ & Relationships & $\mathrm{Rc}$ \\
\hline Timings & $\mathrm{Tm}$ & Classroom layout & $\mathrm{Cl}$ \\
\hline Plenary & $\mathrm{Py}$ & Teacher error & $\mathrm{Te}$ \\
\hline Classroom control & $\mathrm{Crcl}$ & & \\
\hline $\begin{array}{l}\text { Teacher's role/ } \\
\text { teacher's presence }\end{array}$ & $\mathrm{Tr} / \mathrm{Tp}$ & & \\
\hline
\end{tabular}




\section{Appendix B: Example of a reflective practice sheet}

\section{Lesson Subject area: KS 4 \\ Year Group: Year 10}

Targets for this next lesson (these will be the same as the targets set from the previous lesson's reflectivity):

- Not allow the students who are disruptive to of the students to sit on the back row of the classroom.

- To allow the students to make their notes in the lessons and have a format for that.

- Plan extension activities

- $\quad$ Ensure everyone understands the task and that all students stay on task. sit in the lesson together and not to allow any

Reflect on this lesson. What went well and why do you think this was?

- The lesson content was good and appropriate for the lesson. I used video to explain the topic and I ensured that students paid attention by completing a worksheet which they had to fill in throughout.

- The activity was stimulating and I used real and relevant businesses for the activity.

- For the activity I used paired work the students had to complete.

- The controlled assessment lessons were good and the objectives were clear and all students understood what had to be achieved. This was achieved by setting high expectations and providing the students an example layout to complete the task which ensured that they had a lead to follow.

- The table created for the controlled assessment was useful and appropriate, as i referred to the Edexcel guideline for controlled assessment and what the students are required to complete.

- I have noticed that by separating the students, they concentrate more and not allowing students to sit on the back row they are more focused.

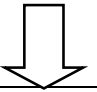

Identify any problems/issues in the lesson. Why you think they occurred?

- I will not allow the disruptive and unmotivated students to sit together in the class.

- I will try to reduce the content for this lower ability set and enable them to make their own notes for the lesson. I provide the students with their own notes on the computer but I will but gaps and spaces in the notes to ensure they are engaged and following the pace of the lesson.

- Plan extension activities even for the lower ability set as some students work faster than others.
- Managing the behaviour of some of the students in this low ability set was difficult one student in particular one male who is very unmotivated to do any work.

- I felt that the content was too much for some students to intake and the students didn't have any method of taking notes.

- Some students almost completed the task and needed an extension activity to keep them busy, I hadn't planned for this. 
I: $\quad$ So, what does education mean to you?

P: $\quad$ I think for me I've always thought education is the key to being able to achieve things in life. I think that wherever you are, and you're born, if you get forged a good education and you can utilise that, then you can go anywhere, and I think I come from a family that has people who are millionaires now who started, you know, in a council estate in Winchester and actually worked their way up. I mean my grandfather was, he was born in the East End of London and packed gun matchsticks, joined the army and used the army to get an education, as did my grandmother, used you know, the [1:03] and so both of them started very lowly and ended up doing very well, they were a major, he was a major in the end, so ... for me I think education is something that you can start low and go anywhere. So that's what I think it is. It's the ability to accu...

I: $\quad$ So from that point it's very important to you obviously.

P: Yes.

I: Do you think any of that influenced why you became a teacher then?

P: I don't know. I think partly ... I suppose I've got a lot of teachers in my family. Well, most of them are professors or lecturers who I have. I have one teacher. The rest are professors or lecturers, so it's always been in the family. I always sort of suppose I did fancy doing it, but it was really when I did training of adults in my job that I actually thought I really like this, and I actually enjoy doing it and I'm good at this, and that was when I wanted to do it.

Table 2: PGCE students and the case participants

\begin{tabular}{|l|l|l|l|l|}
\hline Student & Gender & $\begin{array}{l}\text { Marital } \\
\text { status } \\
\text { (years) }\end{array}$ & $\begin{array}{l}\text { Age at start of PGCE } \\
\text { Children }\end{array}$ \\
\hline Student A & F & M & 34 & 2 \\
\hline Student B & F & P & 26 & 1 \\
\hline Student C & F & M & 29 & 0 \\
\hline Student D & M & S & 24 & 0 \\
\hline Student E & M & M & 49 & 2 \\
\hline Student F & M & M & 33 & 1 \\
\hline
\end{tabular}

( $\mathrm{M}=$ married, $\mathrm{S}=$ single and $\mathrm{P}=$ partner $)$ 
Table 3: Phases of the PGCE year

\begin{tabular}{|l|l|}
\hline Phase 1 (Placement 1) & Oct - Dec \\
\hline Phase 2 (Placement 2) & Jan - April \\
\hline Phase 3 (Placement 2) & April - June \\
\hline
\end{tabular}

Table 4: Categories established from the secondary cycle of coding

\section{Categories:}

Lesson planning

Behaviour

Performance indicators

Classroom activities

Teacher's role

\section{First cycle codes:}

Starter activity, plenary, lesson plan and timings

Engagement of pupils, disruption, lateness, classroom control, classroom layout, external interruptions, gender and rules of the classroom

Targets, assessment, outcomes and lesson objectives

Resources, group work, differentiation, extension work, computers and note taking Instructions, teaching assistant, questioning, pupils' names, teacher led, support, speech, relationship, teacher error, teacher's role, subject knowledge and teacher presence.

Table 5: Phase Comparisons of all the case study participants - weaknesses 


\begin{tabular}{llll}
\hline Coding: & Phase 1 (\%) & Phase 2(\%) & Phase 3 (\%) \\
\hline Classroom Activities & $20(2)$ & $19(2)$ & $11(5)$ \\
Lesson planning & $14(4)$ & $9(5)$ & $17(3)$ \\
Pupil behaviour & $37(1)$ & $39(1)$ & $27(2)$ \\
Performance & $13(5)$ & $18(3)$ & $33(1)$ \\
indicators & & & $12(4)$ \\
Role of the teacher & $16(3)$ & $15(4)$ & \\
\hline ( ) = ranking & & &
\end{tabular}

Table 6: Phase Comparisons of all the case study participants - strengths

\begin{tabular}{llll}
\hline Coding: & Phase 1(\%) & Phase 2(\%) & Phase 3 (\%) \\
\hline Classroom activities & $31(1)$ & $24(3)$ & $21(2)$ \\
Lesson planning & $16(3)$ & $18(5)$ & $15(4)$ \\
Pupil behaviour & $15(4)$ & $22(1)$ & $32(1)$ \\
Performance & $16(3)$ & $18(4)$ & $19(3)$ \\
indicators & & & $13(5)$ \\
Role of the teacher & $22(2)$ & $18(2)$ & \\
\hline ( ) = ranking & &
\end{tabular}




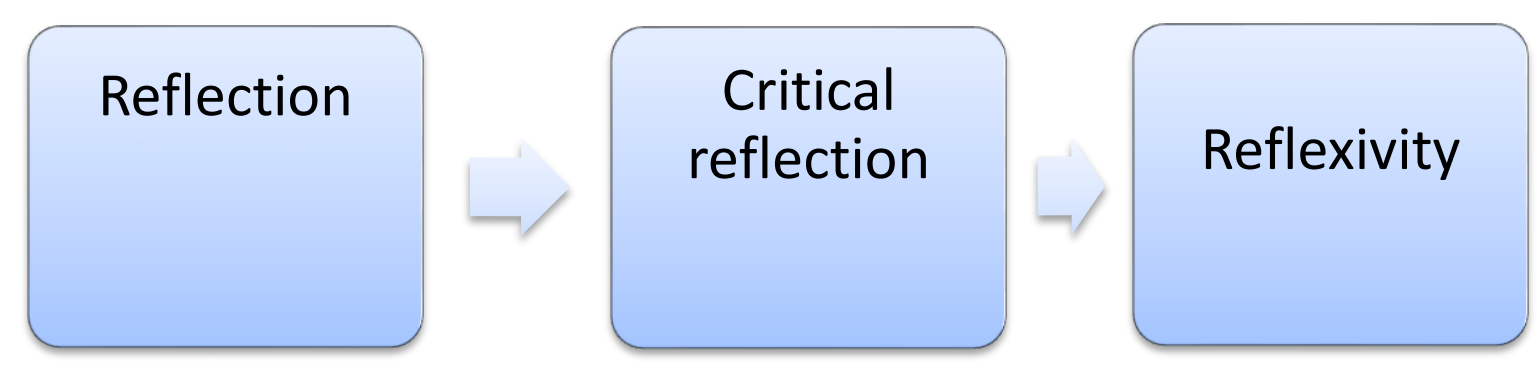

Figure 1: Reflective practice continuum (Adapted from Finlay, 2008)

- immediate response in class

- conscious reflection during the class

- immediate response in class

- conscious reflection after the lesson

- reflections are taken forward to the next lesson

\section{- reflections are taken forward to the next lesson}




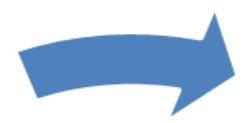

Implement Identify a problem

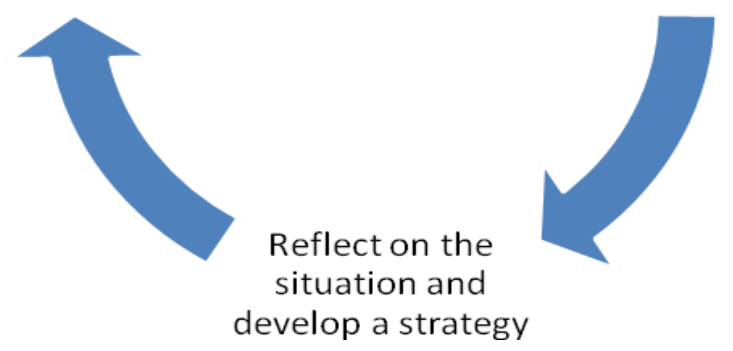

Fig. 3: Reflection for Action (Adapted from: Ghaye et al., 2010)

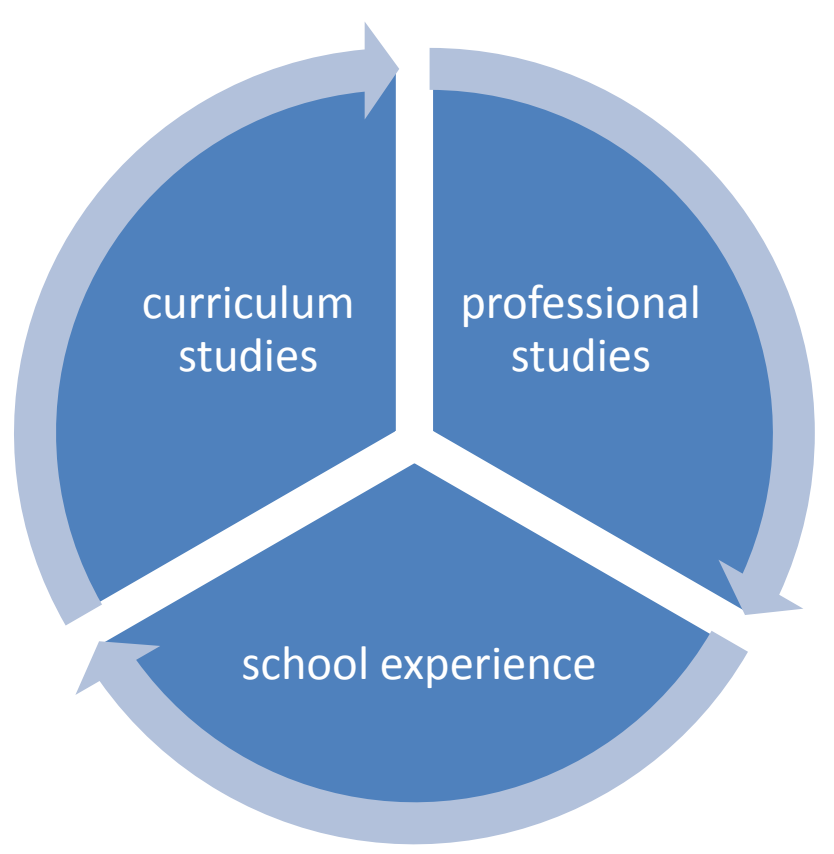

Figure 4: Three strands of the PGCE year 

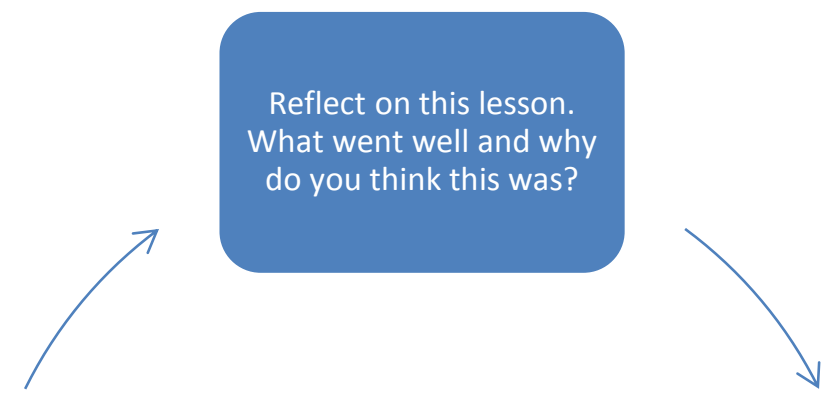

Targets for this next

lesson (these will be the

same as the targets set

from the previous

lesson's reflectivity):

Identify any

problems/issues in the lesson. Why you think

they occurred?
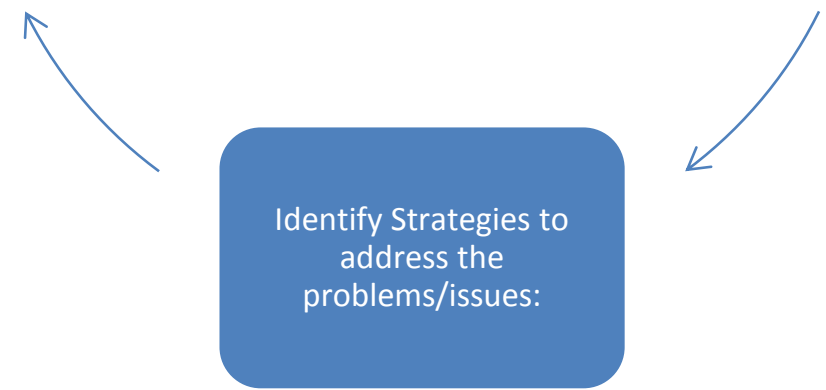

Fig 5: The reflective practice sheets

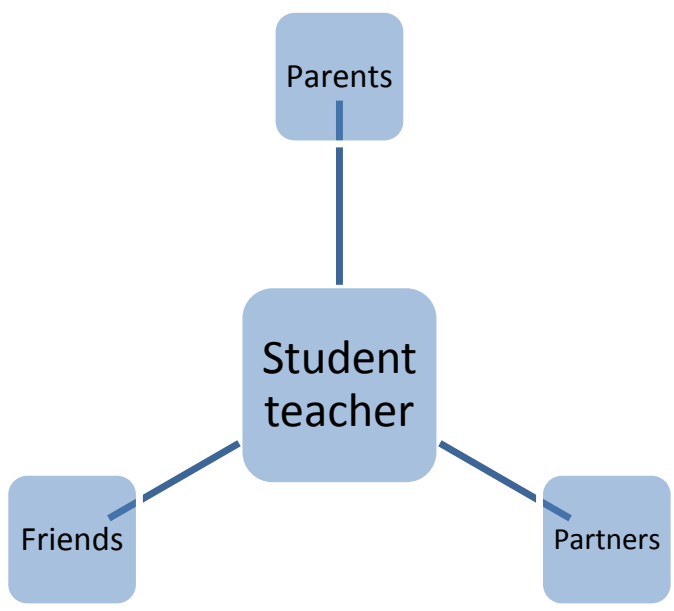

Figure 6: Outer reflective practice community 


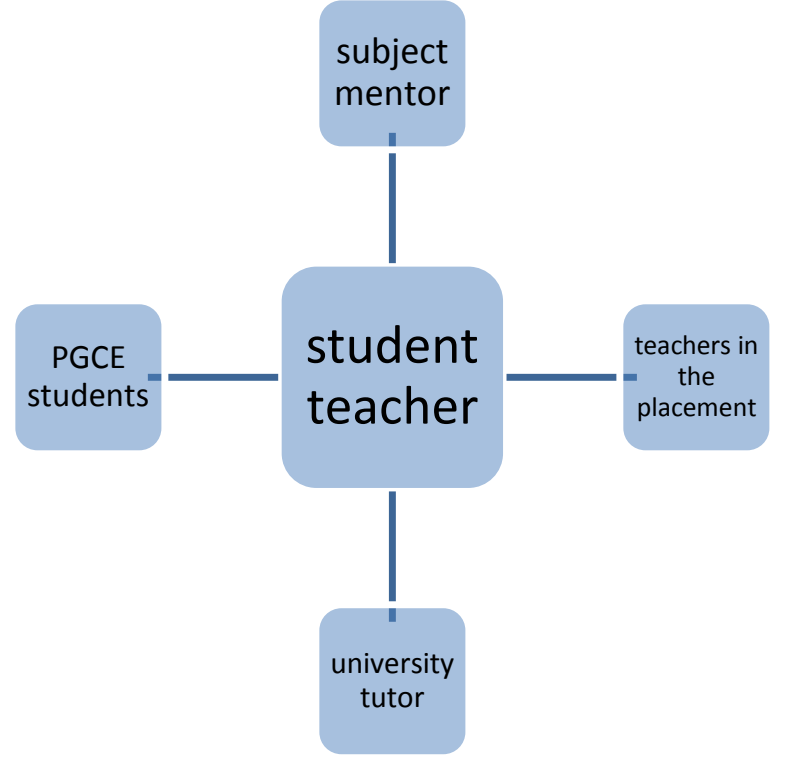

Figure 7: Inner reflective practice community 